San Jose State University

SJSU ScholarWorks

Faculty Publications, Meteorology and Climate Science

Meteorology and Climate Science

February 2011

\title{
The Effect of Zonally Asymmetric Ozone Heating on the Northern Hemisphere Winter Polar Stratosphere
}

\author{
J. P. McCormack \\ Naval Research Laboratory, Washington, D. C., \\ T. R. Nathan \\ University of California - Davis \\ E. C. Cordero \\ San Jose State University, eugene.cordero@sjsu.edu
}

Follow this and additional works at: https://scholarworks.sjsu.edu/meteorology_pub

Part of the Atmospheric Sciences Commons, Climate Commons, and the Meteorology Commons

\section{Recommended Citation}

J. P. McCormack, T. R. Nathan, and E. C. Cordero. "The Effect of Zonally Asymmetric Ozone Heating on the Northern Hemisphere Winter Polar Stratosphere" Geophysical Research Letters (2011).

https://doi.org/10.1029/2010GL045937

This Article is brought to you for free and open access by the Meteorology and Climate Science at SJSU ScholarWorks. It has been accepted for inclusion in Faculty Publications, Meteorology and Climate Science by an authorized administrator of SJSU ScholarWorks. For more information, please contact scholarworks@sjsu.edu. 


\title{
The effect of zonally asymmetric ozone heating on the Northern Hemisphere winter polar stratosphere
}

\author{
J. P. McCormack, ${ }^{1}$ T. R. Nathan, ${ }^{2}$ and E. C. Cordero ${ }^{3}$ \\ Received 21 October 2010; revised 9 December 2010; accepted 23 December 2010; published 3 February 2011.
}

[1] Previous modeling studies have found significant differences in winter extratropical stratospheric temperatures depending on the presence or absence of zonally asymmetric ozone heating $(\mathrm{ZAOH})$, yet the physical mechanism causing these differences has not been fully explained. The present study describes the effect of ZAOH on the dynamics of the Northern Hemisphere extratropical stratosphere using an ensemble of free-running atmospheric general circulation model simulations over the 1 December - 31 March period. We find that the simulations including $\mathrm{ZAOH}$ produce a significantly warmer and weaker stratospheric polar vortex in mid-February due to more frequent major stratospheric sudden warmings compared to the simulations using only zonal mean ozone heating. This is due to regions of enhanced Eliassen-Palm flux convergence found in the region between $40^{\circ} \mathrm{N}-70^{\circ} \mathrm{N}$ latitude and $10-0.05 \mathrm{hPa}$. These results are consistent with changes in the propagation of planetary waves in the presence of $\mathrm{ZAOH}$ predicted by an ozone-modified refractive index. Citation: McCormack, J. P., T. R. Nathan, and E. C. Cordero (2011), The effect of zonally asymmetric ozone heating on the Northern Hemisphere winter polar stratosphere, Geophys. Res. Lett., 38, L03802, doi:10.1029/2010GL045937.

\section{Introduction}

[2] Current climate change assessments have examined atmosphere-ocean general circulation model (GCM) simulations that include the effects of stratospheric ozone depletion in addition to increasing greenhouse gas emissions [e.g., Meehl et al., 2007]. Because of limited computational resources, these long-term simulations typically use a prescribed zonal mean ozone climatology to compute stratospheric heating rates [Cordero and Forster, 2006]. A number of recent studies have suggested that using prescribed zonally symmetric ozone heating, thereby neglecting zonally asymmetric ozone heating (ZOAH) effects, may affect the accuracy of the simulations by failing to capture important radiative-dynamical feedbacks involving ozone heating and planetary wave propagation [Perlwitz et al., 2008; Son et al., 2008; Waugh et al., 2009]. Modeling studies by, e.g., Gabriel et al. [2007], Crook et al. [2008], Waugh et al. [2009], and Gillett et al. [2009] have investigated these feedbacks and found that $\mathrm{ZAOH}$ tends to produce a colder (warmer) winter

\footnotetext{
${ }^{1}$ Space Science Division, Naval Research Laboratory, Washington, D. C., USA.

${ }^{2}$ Department of Air, Land, and Water Resources, University of California, Davis, California, USA.

${ }^{3}$ Department of Meteorology and Climate Science, San Jose State University, San Jose, California, USA.

Copyright 2011 by the American Geophysical Union. 0094-8276/11/2010GL045937
}

polar stratosphere in the Southern (Northern) hemisphere. However, the exact physical mechanisms through which $\mathrm{ZAOH}$ affects the polar winter stratosphere has not yet been fully explained.

[3] An important first step in identifying the mechanisms that may connect $\mathrm{ZAOH}$ with the polar winter stratosphere has been provided by Nathan and Cordero [2007], who present a theoretical framework for understanding how $\mathrm{ZAOH}$ operates on the zonal-mean circulation. Their theory, based on quasigeostrophic formalism, hinges on an ozonemodified refractive index (OMRI) that explicitly shows how $\mathrm{ZAOH}$ modifies the vertical propagation and damping of planetary Rossby waves. Together, these ozone-modified wave properties modulate the Eliassen-Palm flux divergence, a fundamental measure of the planetary wave drag on the zonal-mean circulation.

[4] The goal of the present study is to expand on the onedimensional (in height) quasigeostrophic results of Nathan and Cordero [2007] by examining the effects of $\mathrm{ZAOH}$ on the dynamics of the Northern Hemisphere $(\mathrm{NH})$ winter polar stratosphere using a high-altitude version of the Navy Global Atmospheric Prediction System (NOGAPS) GCM, designated NOGAPS-ALPHA (Advanced Level Physics-High Altitude). This study focuses on the period from 1 December to $31 \mathrm{March}$, since planetary wave activity is much stronger in $\mathrm{NH}$ winter than in Southern Hemisphere (SH) winter. In general, our results agree with earlier studies showing that $\mathrm{ZAOH}$ produces a warmer winter polar stratosphere than zonally symmetric ozone heating. We present the first evidence that $\mathrm{ZAOH}$ acts to increase the chances for a stratospheric sudden warming (SSW) to occur, which is consistent with the changes in planetary wave propagation and damping during NH winter predicted by the OMRI of Nathan and Cordero [2007]. These results may help to understand observed correlations between decadal variations in solar ultraviolet irradiance, stratospheric ozone, and planetary wave activity that have often been cited as possible mechanisms linking solar activity to climate.

\section{Model Description and Methodology}

[5] The GCM component of NOGAPS-ALPHA used in the present study is a global spectral model using a triangular truncation at wave number 79 and 68 hybrid $(\sigma-\mathrm{p})$ vertical levels extending from the surface to $5 \times 10^{-5} \mathrm{hPa}$ ( $\sim 90 \mathrm{~km})$. The effective horizontal grid spacing is $1.5^{\circ}$ in latitude/longitude and the effective vertical grid spacing is $\sim 2 \mathrm{~km}$ in the stratosphere. Shortwave heating and longwave cooling rates are computed using prognostic $\mathrm{O}_{3}$ and $\mathrm{H}_{2} \mathrm{O}$ fields and a fixed vertical profile of $\mathrm{CO}_{2}$. Photochemical sources and sinks of both $\mathrm{O}_{3}$ and $\mathrm{H}_{2} \mathrm{O}$ are specified using the parameterizations of McCormack et al. [2006, 2008], 
(a) NOGAPS-ALPHA T 75N-90N $10 \mathrm{hPa}$

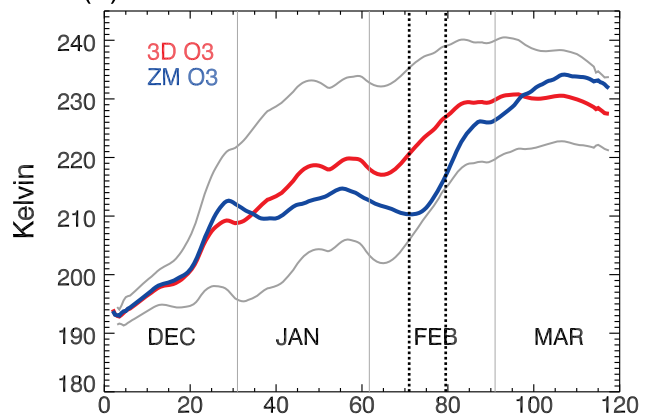

(b) NOGAPS-ALPHA U 60N $10 \mathrm{hPa}$

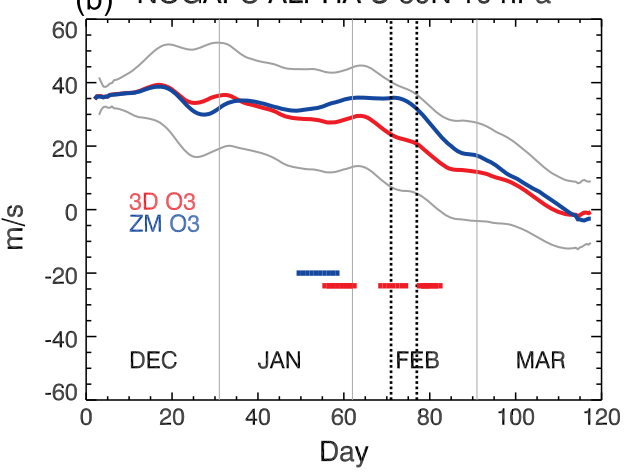

Figure 1. Time series of 3DO3 (red) and ZMO3 (blue) ensemble mean (a) temperatures and (b) zonal winds at $10 \mathrm{hPa}$ beginning 1 December and ending 31 March. Temperatures are averaged over $75^{\circ} \mathrm{N}-90^{\circ} \mathrm{N}$, zonal winds are for $60^{\circ} \mathrm{N}$. Gray curves indicate the standard deviation computed from the 3DO3 ensemble members. Dotted vertical lines indicate when ensemble mean differences are statistically significant at the $95 \%$ confidence level based on Student's t-test. Red and blue horizontal lines in Figure $1 \mathrm{~b}$ indicate dates of stratospheric sudden warmings in the 3DO3 and ZMO3 ensembles, respectively.

respectively. The model is forced at the lower boundary using observed 12-hourly sea surface temperature and surface ice distributions. For a more detailed description of the NOGAPS-ALPHA forecast model, see Eckermann et al. [2009, and references therein] and McCormack et al. [2009, and references therein].

[6] To investigate the effects of $\mathrm{ZAOH}$ on the dynamics of the NH winter polar stratosphere, two sets of free-running NOGAPS-ALPHA model simulations were performed. Each set is initialized identically using analyzed wind, temperature, and constituent fields from the high-altitude NOGAPS-ALPHA data assimilation system [Hoppel et al., 2008; Eckermann et al., 2009]. Each simulation is 120 days in length, beginning in early December and extending to the end of March, with output every 12 hours. The first set of model simulations (designated 3DO3) uses the full 3D prognostic ozone field in the radiative heating and cooling calculations. The second set (designated ZMO3) uses the zonal mean value of the prognostic ozone in the radiative heating and cooling calculations at each longitude grid point for that particular latitude, thus neglecting the $\mathrm{ZAOH}$ component. By taking the difference between the 3DO3 and $\mathrm{ZMO} 3$ results, one can isolate the effects of the $\mathrm{ZAOH}$ component. This approach differs from earlier studies by
Gabriel et al. [2007] and Crook et al. [2008], which imposed zonal asymmetries in the modeled ozone heating rates rather than using self-consistent $3 \mathrm{D}$ ozone fields calculated from the model transport. We note that the zonal mean ozone values are nearly identical between the individual pairs of 3DO3 and $\mathrm{ZMO} 3$ runs throughout most of the time period. Only at high latitudes in February and March below the height of the $10 \mathrm{hPa}$ level $(\sim 30 \mathrm{~km})$ do small $(<10 \%)$ differences emerge, when the model dynamics eventually diverge enough to impact the zonal mean ozone distribution.

[7] To assess the statistical significance of the ZAOH effects, an ensemble of NOGAPS-ALPHA simulations was generated, consisting of 15 pairs of 3DO3 and ZMO3 simulations. Each pair is initialized using the same set of initial conditions. For example, the first three pairs are initialized using the NOGAPS-ALPHA analyses for 00UT 1 December, 5 December, and 9 December 2007. The next three pairs are initialized using the model output fields at hour 12 from the first three simulations, and the following three pairs are initialized using the hour 24 output of the original three simulations, etc.

[8] Comparison of zonal asymmetries in monthly mean ozone and temperature fields from the 3DO3 ensemble at $60^{\circ} \mathrm{N}$ and $10 \mathrm{hPa}$ with observations from the NOGAPSALPHA assimilation for December 2007-February 2008 (not shown) shows good overall agreement. This lends confidence in our ability to accurately describe the effects of $\mathrm{ZAOH}$ on the polar winter stratosphere.

\section{Results}

[9] Figure 1a compares the time evolution of the ensemble mean 3DO3 (red curve) and ZMO3 (blue curve) model temperatures at $10 \mathrm{hPa}$ averaged over $75^{\circ} \mathrm{N}-90^{\circ} \mathrm{N}$ latitude. For the first two weeks of the simulations, the 3DO3 and ZMO3 ensemble means are indistinguishable from each other. Throughout most of January and early February the $3 \mathrm{DO} 3$ ensemble mean is $\sim 5-6 \mathrm{~K}$ warmer than the ZMO3 ensemble mean. In mid-February this difference grows to $12 \mathrm{~K}$. To illustrate the ensemble spread in the modeled $10 \mathrm{hPa}$ polar temperatures, values of the 3DO3 ensemble average plus/minus its standard deviation are plotted in Figure 1a as gray curves. A Student's T-test is performed to assess the significance of the differences between the ensemble means at each time step. We find statistically significant temperature differences at the $95 \%$ confidence level over the Northern polar cap at $10 \mathrm{hPa}$ on days $71-80$, when the largest differences between the 3DO3 and ZMO3 ensembles occur.

[10] Figure $1 \mathrm{~b}$ plots the time evolution of the ensemble zonal mean zonal winds at $10 \mathrm{hPa}$ between $50^{\circ} \mathrm{N}-60^{\circ} \mathrm{N}$ latitude in a manner similar to Figure 1a (positive values denote westerly winds). Differences in the ensemble mean winds are negligible throughout much of December. In January, the 3DO3 mean westerly winds are $\sim 5 \mathrm{~m} \mathrm{~s}^{-1}$ weaker compared to the ZMO3 winds. By mid-February, the 3DO3 mean westerly winds are 10-14 $\mathrm{m} \mathrm{s}^{-1}$ weaker than the ZMO3 case, concurrent with the largest temperature differences in Figure 1a.

[11] Figures 2 and 3 plot the latitude and altitude dependences of the monthly zonal mean temperature and zonal wind differences (3DO3-ZMO3) for December, January, 

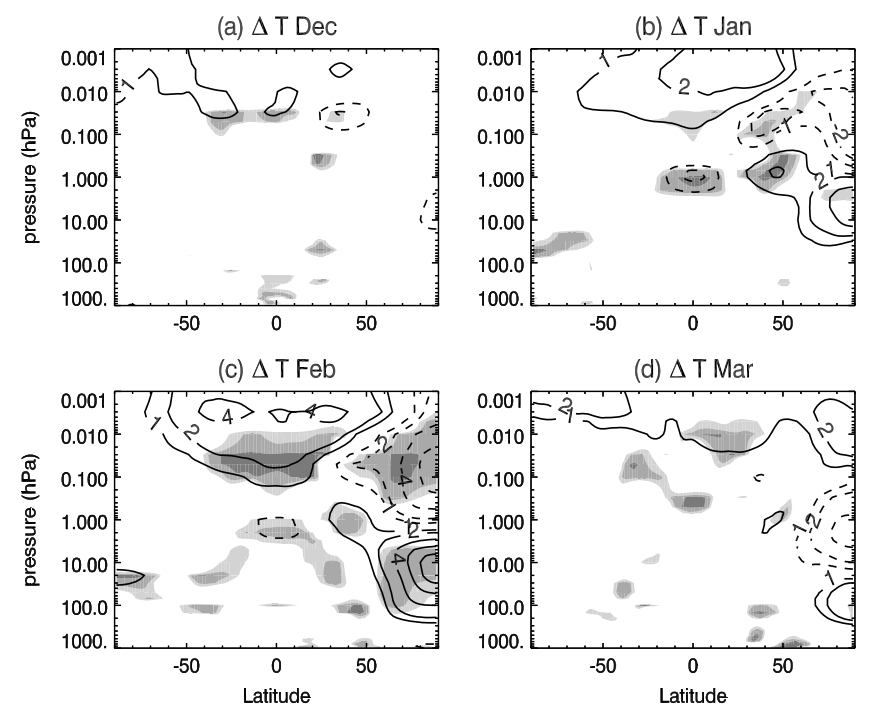

Figure 2. Monthly zonal mean temperature differences between the $3 \mathrm{DO} 3$ and $\mathrm{ZMO} 3$ ensembles $(\Delta \mathrm{T}=3 \mathrm{DO} 3$ minus ZMO3) for (a) December, (b) January, (c) February, and (d) March. Contours drawn at $\pm 1, \pm 2, \pm 4, \pm 6$, and \pm 8 K. Solid (dashed) contours denote positive (negative) values. Shading indicates statistically significant differences at the $95 \%$ (light shading) and 99\% (dark shading) confidence levels.

February, and March, respectively. The temperature response in December (Figure 2a) is negligible, while in January (Figure 2b) there is evidence of a warming (cooling) in the midlatitude upper stratosphere (lower mesosphere) of $\sim 2 \mathrm{~K}$. The largest temperature response is found in February, with a statistically significant warming in excess of $8 \mathrm{~K}$ in the polar stratosphere near $10 \mathrm{hPa}$. We also note a significant warming (cooling) in the equatorial (polar) mesosphere during this time. By March (Figure 2d) the polar stratospheric warming is much weaker and limited to the region near $100 \mathrm{hPa}$, while the upper polar stratosphere exhibits cooling of $\sim 4 \mathrm{~K}$, although neither of these features are statistically significant.
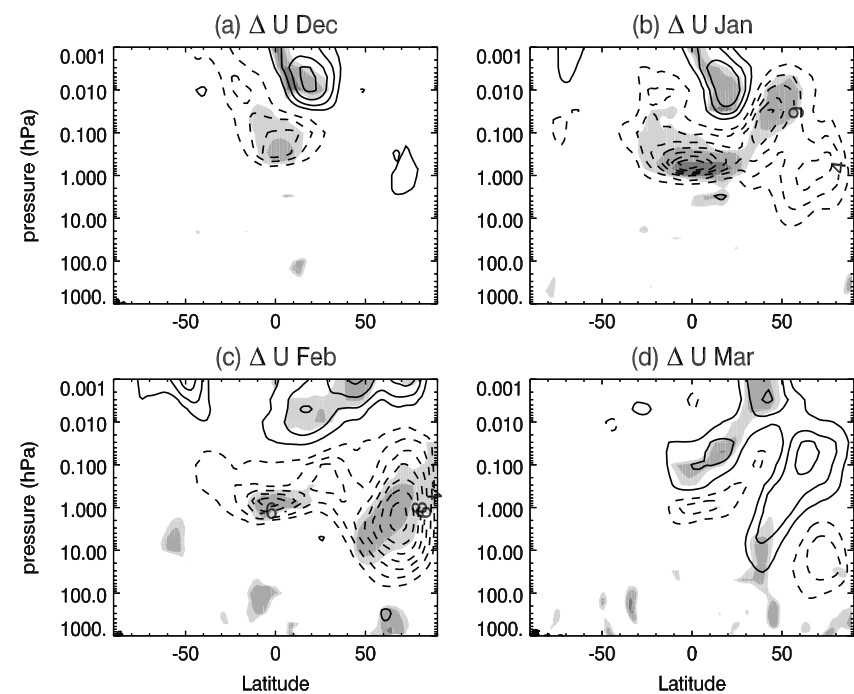

Figure 3. As in Figure 2, but for zonal mean zonal winds. Contour interval is $\pm 2 \mathrm{~m} \mathrm{~s}^{-1}$, zero contour is suppressed.

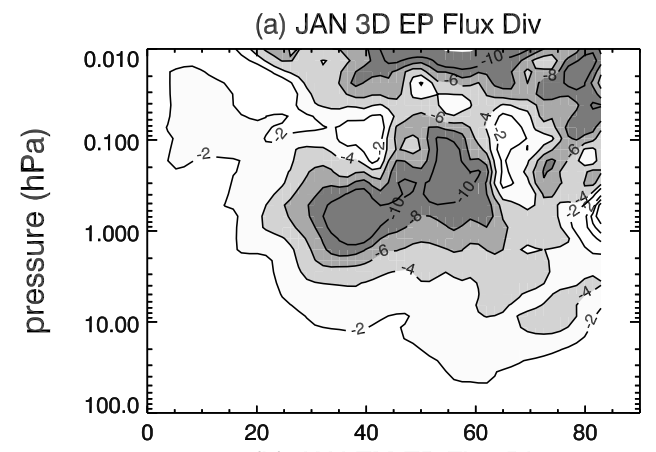

(b) JAN ZM EP Flux Div

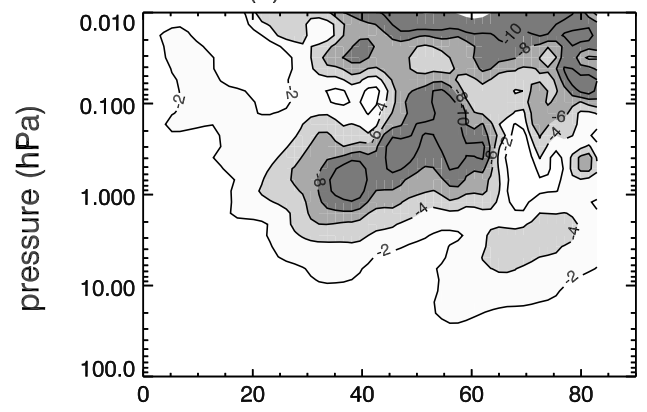

(c) JAN $\triangle$ EP Flux Div

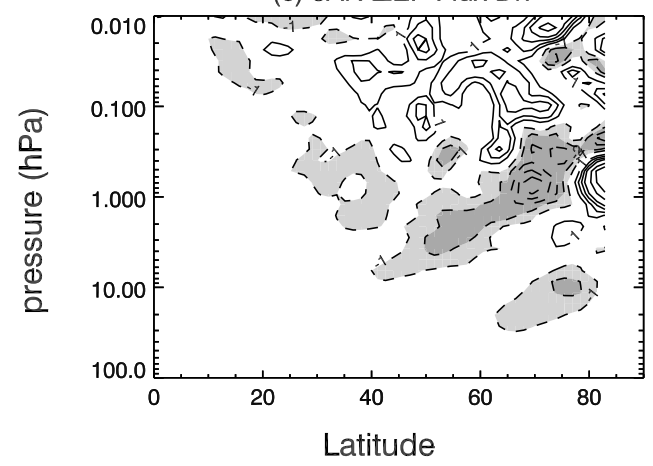

Figure 4. (a) $3 \mathrm{DO} 3$ ensemble mean EP flux divergence for January over the Northern Hemisphere. Contours drawn at $-2,-4,-6,-8$, and $-10 \mathrm{~m} \mathrm{~s}^{-1}$ day $^{-1}$, values greater than $2 \mathrm{~m} \mathrm{~s}^{-1}$ day $^{-1}$ are shaded; (b) ZMO3 ensemble mean EP flux divergence for January, as in Figure 4a; (c) difference plot of EP flux divergence (3DO3 minus ZMO3) for January, contours drawn every $1 \mathrm{~m} \mathrm{~s}^{-1}$ day $^{-1}$. Dashed contours denote negative values, and values less then $1 \mathrm{~m} \mathrm{~s}^{-1}$ day $^{-1}$ are shaded.

[12] The zonal wind response in December (Figure 3a) consists of a weak (2-3 m s${ }^{-1}$ ) easterly (westerly) anomaly in the lower (upper) equatorial mesosphere. The locations of these negative (positive) zonal wind anomalies in December coincide with an equatorward (poleward) shift in the location of the zero wind line (not shown). In January (Figure 3b), more pronounced easterly anomalies exceeding $10 \mathrm{~m} \mathrm{~s}^{-1}$ appear near the equatorial stratopause and in the extratropical upper stratosphere/lower mesosphere. By February (Figure 3c), the extratropical easterly anomaly has propagated poleward and downward, similar to the positive temperature anomaly in Figure 2.

[13] In general, the temperature and zonal wind responses in Figures 2 and 3 present a consistent picture of a warmer polar stratosphere and weaker polar vortex during January and February in the presence of ZAOH. The polar strato- 
spheric warming/mesospheric cooling signature in Figure 2c is characteristic of a SSW. An examination of the wind fields from the 30 individual ensemble members found 5 winters when a major SSW occurred during January or February. (Here we define a major SSW as a reversal of the zonal mean zonal wind at $10 \mathrm{hPa}$ and $60^{\circ} \mathrm{N}$ from westerly to easterly flow.) Of these five cases, four took place in 3DO3 simulations (i.e., where $\mathrm{ZAOH}$ is included) and one took place in a $\mathrm{ZMO} 3$ simulation. Days with zonal mean easterly flow at $10 \mathrm{hPa}$ and $60^{\circ} \mathrm{N}$ from the $3 \mathrm{DO} 3$ and $\mathrm{ZMO} 3$ ensembles are indicated by the red and blue horizontal lines, respectively, in Figure $1 \mathrm{~b}$.

[14] To better understand the origin of the temperature and zonal wind differences due to the effects of ZAOH that first emerge in January (Figure 1), we examine how the modeled planetary wave activity affects the zonal mean zonal winds through differences in the Eliassen-Palm (EP) flux divergence between the $3 \mathrm{DO} 3$ and $\mathrm{ZMO} 3$ cases. Figure $4 \mathrm{a}$ plots the $3 \mathrm{DO} 3$ ensemble monthly mean EP-flux divergence over the Northern Hemisphere for January. Negative values, denoting convergence or an easterly acceleration, are present throughout much of the extratropical upper stratosphere and mesosphere. The ZMO3 EP-flux divergence for January (Figure 4b) shows generally smaller negative values of the EP flux divergence in the extratropical stratosphere, particularly between $60^{\circ} \mathrm{N}-70^{\circ} \mathrm{N}$ near $1 \mathrm{hPa}$. Figure $4 \mathrm{c}$ plots the difference between the EP flux divergence fields in Figures $4 \mathrm{a}$ and $4 \mathrm{~b}$. Overall, we find greater planetary wave drag on the zonal mean flow in January in the presence of $\mathrm{ZAOH}$. These results are consistent with the temperature and zonal wind responses described above. Specifically, stronger (weaker) EP flux convergence is associated with warmer (colder) polar stratospheric temperatures and a weaker (stronger) polar vortex in the presence (absence) of $\mathrm{ZAOH}$.

\section{Summary and Discussion}

[15] An ensemble of free-running GCM simulations has been used to isolate the effects of $\mathrm{ZAOH}$ on the temperature and wind distributions in the Northern winter stratosphere. We find that $\mathrm{ZAOH}$ produces a warmer and weaker polar vortex during January and February, and a higher frequency of major SSWs in mid-to-late February.

[16] Although direct comparisons between the NOGAPSALPHA model results presented here and the quasigeostrophic model results of Nathan and Cordero [2007] are difficult, both models show that $\mathrm{ZAOH}$ produces significant changes in the EP-flux divergence and thus the zonalmean zonal wind. In the extratropics, both models show that these $\mathrm{ZAOH}$-induced changes extend from near $\sim 10 \mathrm{hPa}$ $(\sim 30 \mathrm{~km})$ where wave-ozone advection and ozone photochemistry both contribute to the ZAOH effect, up to $\sim 0.01 \mathrm{hPa}$ $(\sim 65 \mathrm{~km})$ where the ZAOH effect is controlled by ozone photochemistry. Overall, the present study indicates that in the absence of ZAOH, imposing only zonally symmetric ozone heating in a GCM will likely produce a colder, stronger $\mathrm{NH}$ winter polar vortex and fewer SSWs.

[17] The temperature differences in Figure 1a are generally similar to earlier results from Gillett et al. [2009] in that we find warmer winter polar stratospheric temperatures when $\mathrm{ZAOH}$ is included. However, Gillett et al. [2009] reported a maximum warming of approximately $3 \mathrm{~K}$ at $10 \mathrm{hPa}$ in December only, with no statistically significant warming in January or February. While the exact reasons for this discrepancy are unknown at this time, we note that the higher frequency of major SSWs in the 3DO3 ensemble is primarily responsible for the statistically significant temperature and wind responses reported here. Many middle atmosphere GCMs tend to under-predict the occurrence of SSWs [Charlton et al., 2007]. A lack of major SSWs in the modeling study of Gillett et al. [2009] could be one possible explanation for this discrepancy.

[18] Based on these results, a more comprehensive investigation of $\mathrm{ZAOH}$ effects covering different time periods (e.g., over both $\mathrm{NH}$ and $\mathrm{SH}$ winter for different years) is warranted. These will examine the relative importance of ozone-modified wave propagation versus wave damping in modulating the planetary wave drag and thus the zonalmean circulation.

[19] Acknowledgments. We thank John Albers helpful discussions during the preparation of this manuscript. JPM was supported in part by the Office of Naval Research and in part by the NASA Heliophysics Living With a Star Program award NNH08AI67I. TRN was supported in part by NSF grant ATM-0733698 and by NASA/NRL grant NNH08AI67I. ECC was supported by NSF's Faculty Early Career Development (CAREER) Program, grant ATM-0449996.

\section{References}

Charlton, A. J., et al. (2007), A new look at stratospheric sudden warmings. Part II: Evaluation of numerical model simulations, J. Clim., 20, 470 488, doi:10.1175/JCLI3994.1.

Cordero, E., and P. M. D. F. Forster (2006), Stratospheric variability and trends in models used for the IPCC AR4, Atmos. Chem. Phys., 6, 5369-5380.

Crook, J. A., N. P. Gillett, and S. P. E. Keeley (2008), Sensitivity of Southern Hemisphere climate to zonal asymmetry in ozone, Geophys. Res. Lett., 35, L07806, doi:10.1029/2007GL032698.

Eckermann, S. D., K. W. Hoppel, L. Coy, J. P. McCormack, D. E. Siskind, K. Nielsen, A. Kochenash, M. H. Stevens, and C. R. Englert (2009), High-altitude data assimilation system experiments for the Northern Hemisphere summer mesosphere season of 2007, J. Atmos. Sol. Terr. Phys., 71, 531-551.

Gabriel, A., D. Peters, I. Kirchner, and H.-F. Graf (2007), Effect of zonally asymmetric ozone on stratospheric temperature and planetary wave propagation, Geophys. Res. Lett., 34, L06807, doi:10.1029/2006GL028998.

Gillett, N. P., J. F. Scinocca, D. A. Plummer, and M. C. Reader (2009), Sensitivity of climate to dynamically-consistent zonal asymmetries in ozone, Geophys. Res. Lett., 36, L10809, doi:10.1029/2009GL037246.

Hoppel, K. W., N. L. Baker, L. Coy, S. D. Eckermann, J. P. McCormack, G. Nedoluha, and D. E. Siskind (2008), Assimilation of stratospheric and mesospheric temperatures from MLS and SABER in a global NWP model, Atmos. Chem. Phys., 8, 6103-6116.

McCormack, J. P., S. D. Eckermann, D. E. Siskind, and T. J. McGee (2006), CHEM2D-OPP: A new linearized gas-phase ozone photochemistry parameterization for high-altitude NWP and climate models, Atmos. Chem. Phys., 6, 4943-4972.

McCormack, J. P., K. H. Hoppel, and D. S. Siskind (2008), Parameterization of middle atmospheric water vapor photochemistry for high-altitude NWP and data assimilation, Atmos. Chem. Phys. Discuss., 8, 13,99914,032 .

McCormack, J. P., L. Coy, and K. W. Hoppel (2009), Evolution of the quasi 2-day wave during January 2006, J. Geophys. Res., 114, D20115, doi:10.1029/2009JD012239.

Meehl, G. A., et al. (2007), Global climate projections, in Climate Change 2007: The Physical Science Basis. Contribution of Working Group I to the Fourth Assessment Report of the Intergovernmental Panel on Climate Change, edited by S. Solomon et al., pp. 747-845, Cambridge Univ. Press, Cambridge, U. K.

Nathan, T. R., and E. C. Cordero (2007), An ozone-modified refractive index for vertically propagating planetary waves, J. Geophys. Res., 112, D02105, doi:10.1029/2006JD007357. 
Perlwitz, J., S. Pawson, R. L. Fogt, J. E. Nielsen, and W. D. Neff (2008), Impact of stratospheric ozone hole recovery on Antarctic climate, Geophys. Res. Lett., 35, L08714, doi:10.1029/2008GL033317.

Son, S.-W., et al. (2008), The impact of stratospheric ozone recovery on the Southern Hemisphere westerly jet, Science, 320, 1486-1489, doi:10.1126/science. 1155939 .

Waugh, D. W., L. Oman, P. A. Newman, R. S. Stolarski, S. Pawson, J. E. Nielsen, and J. Perlwitz (2009), Effect of zonal asymmetries in stratospheric ozone on simulated Southern Hemisphere climate trends, Geophys. Res. Lett., 36, L18701, doi:10.1029/2009GL040419.

E. C. Cordero, Department of Meteorology and Climate Science, San Jose State University, San Jose, CA 95192, USA.

J. P. McCormack, Space Science Division, Naval Research Laboratory, 4555 Overlook Ave. SW, Washington, DC 20375, USA. (john. mccormack@nrl.navy.mil)

T. R. Nathan, Atmospheric Science Program, Department of Land, Air and Water Resources, University of California, Davis, CA 95616, USA. 